\title{
Brown Bowel Syndrome: A Rare Complication in Diseases Associated with Long-Standing Malabsorption
}

\author{
Heinz Albrecht ${ }^{a} \quad$ Alexander Hagel $^{a} \quad$ Thomas de Rossi $^{a} \quad$ Tilman T. Rau $^{b}$ \\ Thomas Kirchner $^{c}$ Markus F. Neurath ${ }^{\mathrm{a}}$ Martin Raithel ${ }^{\mathrm{a}}$ \\ ${ }^{a}$ Department of Internal Medicine 1 and ${ }^{\mathrm{b}}$ Institute of Pathology, University of Erlangen-Nuremberg, Erlangen, and \\ c Department of Pathology, Ludwig Maximilian University Munich, Munich, Germany
}

\section{Key Words}

Brown bowel syndrome - Malabsorption - Lipofuscinosis .

Vitamin $\mathrm{E}$

\begin{abstract}
Background/Aims: Longtime chronic malabsorption may among other things cause a lack of liposoluble vitamins. Vitamin E deficiency can lead to formation of lipofuscin aggregates. Its deficiency is also associated with an increased lipofuscinosis of the bowel, i.e. brown bowel syndrome. Methods: Systematic research via Medline on brown bowel syndrome, lipofuscinosis, and vitamin E deficiency was performed. We combined our own clinical experience and a review of the literature for this paper. Its goal is to inform about the possible consequences of severe malabsorption and brown bowel syndrome. Results: Systematic data about the occurrence of severe malabsorption and brown bowel syndrome are rare. Only about 27 scientific reports can be found on this subject. Brown bowel syndrome is found mostly in conjunction with vitamin E deficiency and lipofuscinosis of the bowel. The clinical findings are caused by both malabsorption and lipofuscinosis. Case reports show a therapeutic effect of vitamin E. Conclusion: Vitamin deficiency caused by longtime chronic malabsorption can lead to the
\end{abstract}

development of brown bowel syndrome, which is seen as the expression of lipofuscinosis of the bowel, and can cause further clinical disorders. Patients with malabsorption should therefore be monitored regarding their vitamin $\mathrm{E}$ levels.

(c) 2014 S. Karger AG, Basel

\section{Introduction}

Chronic long-term or severe malabsorption can be the cause of a recurring or persisting deficiency in proteins, lipids, electrolytes, vitamins, and other trace elements. In particular, a deficit in fat-soluble vitamins such as vitamin $\mathrm{A}, \mathrm{D}, \mathrm{E}$, and $\mathrm{K}$ is associated with symptoms of dry skin, concentration disorders, fatigue, poor wound healing, coagulatory disorders, increased susceptibility to infection, and other cognitive and neurological deficits [1]. The main function of vitamin $\mathrm{E}$ (tocopherol) as an antioxidant membrane lipid is to guard against auto-oxidation or pathological oxidation induced by free radicals; thus, a deficiency in this vitamin causes damage to the phospholipid layer of the mitochondrial membrane via free radicals with the resulting development of lipofuscin deposits [2]. Such a deficiency is also associated with an increase

\section{KARGER}

E-Mail karger@karger.com

www.karger.com/dig (c) 2014 S. Karger AG, Base

0012-2823/14/0892-0105\$39.50/0
Dr. med. Heinz Albrech

Department of Internal Medicine 1, University of Erlangen-Nuremberg Ulmenweg 18

DE-91054 Erlangen (Germany)

E-Mail heinz.albrecht@uk-erlangen.de 


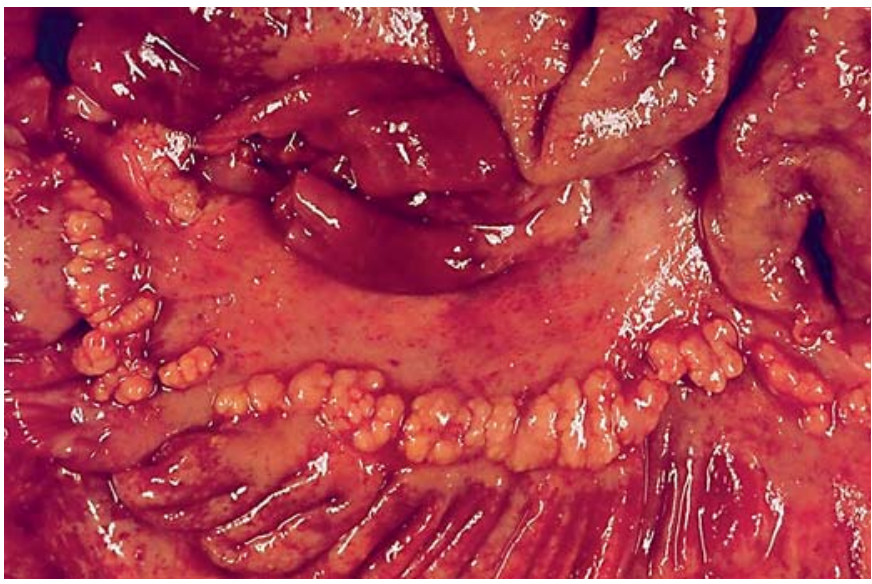

Fig. 1. Small bowel preparation of brown bowel syndrome after 20 years of long-standing malabsorption in congenital intestinal lymphangiectasia. Mucosal surface and various tissue layers (muscularis propria) are characterized macroscopically by an orangebrown appearance as a sign of diffuse intestinal lipofuscinosis.

in lipofuscinosis of the bowel, i.e. brown bowel syndrome $[3,4]$.

The aim of this study is to familiarize the reader more closely with the symptoms and complications of brown bowel syndrome as the result of an underlying malabsorption disorder. We present the results of a literature search and our own clinical experience.

\section{Definition of Brown Bowel Syndrome}

Brown bowel syndrome was first reported in the literature in 1963 and signifies lipofuscinosis mainly in the small bowel that is characterized macroscopically by an orange-brown appearance [5] (fig. 1). In addition to the atrophic villi that can be viewed microscopically as a sign of an underlying malabsorptive disorder, a brown coloring particularly of the apical enterocytes demonstrates the increased lipofuscin deposits (fig. 2).

These lipofuscin aggregates are found inside the cell, mainly in the smooth muscle cells of the muscular coat, but also in the muscular layer of the mucosa [6-9]. Whereas more lipofuscin accumulates in the heart, liver tissue, and adrenal glands with aging, the mechanism underlying its development has not yet been determined. It is thought to be a degradation product of degenerating mitochondria, and in advanced brown bowel syndrome it has also been detected - though rarely - in other organs, such as the thyroid or intestinal lymph nodes $[3,8,10,11]$.

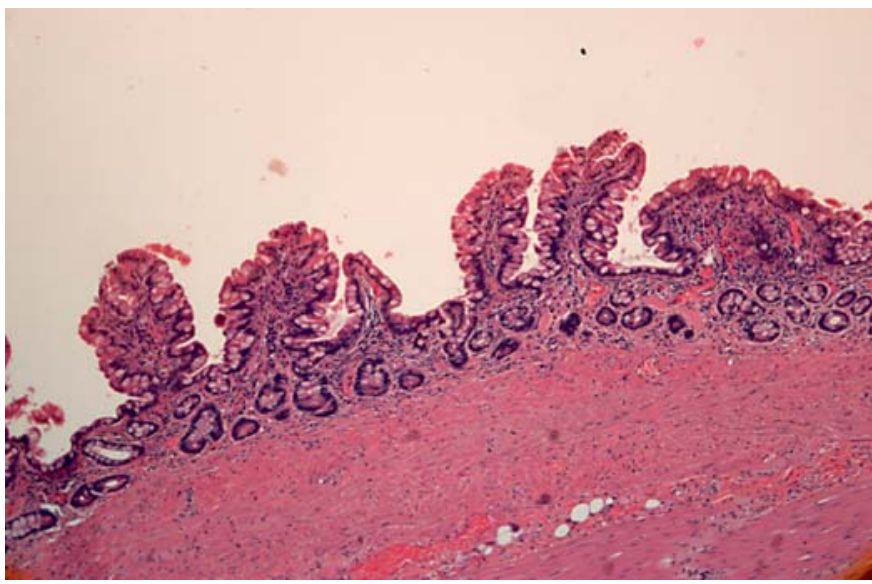

Fig. 2. Histological section from jejunal mucosa with villous reduction and atrophy in chronic malabsorption with brown bowel syndrome. Of note are apical enterocytes which contain moderate brown inclusions as a sign of lipofuscin aggregates.
Other authors have suggested that autophagocytotic processes may represent a model for the formation of lipofuscin [6-8].

\section{Presumed Pathogenesis and Clinical Symptoms}

The cause of this particular form of lipofuscinosis, one that is associated with brown coloration in the small bowel, has not been elucidated yet. It is generally thought to be due to chronic vitamin E deficiency, which is the result of deficient enteral uptake of fat-soluble tocopherol in malabsorption syndromes such as celiac disease [12-14].

Deficiencies of a range of nutrients, including vitamin $\mathrm{E}$, are a common complication following malabsorptive forms of obesity surgery. Indeed, brown bowel syndrome was recently reported in a patient in whom a jejunoileal bypass had been created 26 years previously [2]. So even a 'jejunoileal bypass' as an unusual old procedure may be associated with brown bowel syndrome [2]. Over the course of time the vitamin E deficiency or lipofuscinosis may cause neuronal functional disorders that, as a result, affect bowel motility to a considerable degree [15].

Advanced brown bowel syndrome presents several symptoms in addition to the signs of the underlying malabsorption disorder. This includes general dystrophia, weight loss, protein deficiency edema, motility problems (e.g. vomiting, flatulence, and pseudo-obstructions), liver cirrhosis, signs of vitamin deficiency involving severe os- 
Table 1. Summary of diseases associated with or predisposing to the development of brown bowel syndrome

\begin{tabular}{|c|c|c|}
\hline Keynotes & Example & Reference \\
\hline Malabsorption & celiac disease & {$[14,28]$} \\
\hline \multirow[t]{2}{*}{ Maldigestion } & chronic pancreatitis & {$[23]$} \\
\hline & liver disease, cholestasis & {$[11]$} \\
\hline \multirow[t]{2}{*}{ Chronic inflammation } & Crohn's disease & {$[27]$} \\
\hline & ulcerative enteritis & {$[25]$} \\
\hline \multirow[t]{4}{*}{ Motility disturbances } & $\begin{array}{l}\text { intestinal } \\
\text { pseudo-obstruction }\end{array}$ & {$[4]$} \\
\hline & bowel atonia & {$[7]$} \\
\hline & $\begin{array}{l}\text { anorectal functional } \\
\text { disturbances }\end{array}$ & {$[29]$} \\
\hline & intestinal atresia & {$[26]$} \\
\hline \multirow[t]{2}{*}{$\begin{array}{l}\text { Association with } \\
\text { malignancy }\end{array}$} & $\begin{array}{l}\text { gastrointestinal } \\
\text { adenocarcinoma }\end{array}$ & {$[18]$} \\
\hline & lymphoma & {$[24]$} \\
\hline Postoperative conditions & $\begin{array}{l}\text { obesity surgery } \\
\text { jejunoileal bypass }\end{array}$ & {$[2]$} \\
\hline
\end{tabular}

Vitamin E deficiency a- $\beta$-lipoproteinemia [30]

teoporosis, abdominal pain, diarrhea, and steatorrhea $[11,16]$.

Complications such as electrolytic shift, protein and nutrient deficiency with resulting cachexia, and increased susceptibility to infection can develop from severe malabsorption. They can also be the result of morphological changes in the affected bowel segment such as bowel atonia, intussusception, and intestinal pseudo-obstruction or gastrointestinal bleeding $[4,7,17-20]$. Such complications can be fatal.

\section{Association with Malignant Diseases}

The concomitant presentation of brown bowel syndrome and carcinoma in the small intestine has only been reported in one isolated case so far [18]. However, brown bowel syndrome has been reported to arise concomitantly with other gastrointestinal adenocarcinomas more frequently, but precise data are still lacking because of its rarity [21-23].

Brown Bowel Syndrome
According to current data, it is difficult in general to determine whether the disease underlying the brown bowel syndrome is responsible for the increased risk of carcinoma in patients with celiac disease and chronic pancreatitis. In other words, it is not known whether the chronic inflammation alone contributes to neoplastic progression or whether the vitamin E deficiency resulting from chronic malabsorption is responsible for this [23].

\section{Other Diseases Associated with Brown Bowel Syndrome}

Table 1 presents several diseases in which the development of brown bowel syndrome has been reported.

In some studies, a pronounced vitamin E deficiency has been discovered, which could help explain the association with brown bowel syndrome. To date, however, a prospective observation of decreased vitamin E levels to development of the brown bowel syndrome has not yet been established in humans. Following malabsorptive techniques of obesity surgery (in particular biliopancreatic diversion), vitamin E deficiency is common. Screening and appropriate supplementation (not only of vitamin E deficiency, but also of a wide range of other macroand micronutrients) are therefore a crucial aspect of routine long-term follow-up [2].

Brown bowel syndrome has mainly been found to be associated with malabsorptive disorders of the small bowel, such as celiac disease and intestinal lymphoma [4, 23, 24]. Furthermore, an association between congenital bowel malformations such as small intestinal atresia has also been established [26].

Lipofuscin aggregates have also been discovered in the smooth muscle cells of the muscular layer of the mucosa in patients with chronic inflammatory bowel diseases such as Crohn's disease and in severe cases of ulcerative enteritis [7, 27]. In one case report, brown bowel syndrome developed in a patient with known Crohn's disease within 5 years [27]. Here, the typical lipofuscin deposits were found in the cytoplasm and in the perinuclear regions of the smooth muscle cells, which gave rise to the notion that brown bowel syndrome might possibly be a 'mitochondrial myopathy'. The loss of mitochondrial function and resulting disorder in energy production ultimately causes atrophy and atonia of the smooth muscle $[3,4]$. In fact, the damage to the smooth muscle of the bowel present in existing brown bowel syndrome can explain many functional symptoms or pathophysiological findings, including bowel atonia, intussusception, intes- 
tinal pseudo-obstruction, various anorectal functional disturbances, etc. $[4,7,17]$.

Exocrine pancreas insufficiency can cause inadequate resorption of fat-soluble vitamins (vitamins $\mathrm{A}, \mathrm{D}, \mathrm{E}$, and K) $[31,32]$. Chronic vitamin E deficiency can then induce brown bowel syndrome $[12,13]$.

Likewise, severe malabsorption syndrome and celiac disease are also both associated with chronic vitamin $\mathrm{E}$ deficiency, which in turn produces the lipofuscin aggregates typical for brown bowel syndrome and the macroscopically apparent brown coloration of the small bowel. Indeed, a case report was published concerning a patient in whom radiologically visible changes were detected that were similar to those observed in intestinal lymphoma [24]. Histologically, brown bowel syndrome was confirmed in this patient by a transmural biopsy taken from a segment of the small bowel in which a brown coloration had been observed. The authors postulate that the lipofuscin deposits in the muscular layer of the mucosa caused the changes that could be detected radiologically and which are similar to the radiological changes observed for intestinal lymphoma [24].

Micronutrient metabolism deficiency can also be caused by various other malabsorption syndromes. Here, the liver should be mentioned in particular, as it is the organ primarily responsible for metabolism. Via biliary secretion, the liver regulates fat digestion and the absorption of fat-soluble vitamins. In the literature, case reports can be found of patients with liver cirrhosis and resulting malabsorption and brown bowel syndrome [11]. However, no studies have been performed in which serum vitamin E levels were correlated with the extent of nutritional deficiency and the development of brown bowel syndrome.

One case study reported massive bleeding in the lower gastrointestinal tract in conjunction with the presence of brown bowel syndrome [20]. The authors postulated that the functional loss of the mitochondria in the smooth muscle cells, which is typical for this disease, contributed to or caused the bleeding. Histologically, lipofuscin deposits were demonstrated in the smooth muscle cells of the arterial and venous walls, which ultimately caused hemorrhagia and persistent bleeding [20].

\section{Diagnosis and Treatment}

Among many other serological parameters (e.g. C-reactive protein, albumin, total protein, transglutaminase IgA, etc.), serum levels of fat-soluble vitamins and carot- enoids are determined for the diagnosis of malabsorptive disorders. In addition, the fat content in stool samples can be measured to gain further information. Imaging procedures (abdominal ultrasound, MRI, barium enema, and $\mathrm{CT}$ ) and endoscopic examinations including multiple biopsies from the small bowel should also be performed.

The term vitamin $\mathrm{E}$ constitutes a collective name for all natural and synthetic tocol and tocotrienol derivatives, which qualitatively demonstrate the biological activity of a-tocopherol $[33,34]$. Tocopherol is the umbrella term for all mono-, di-, and trimethyl tocotrienols. To determine the levels of the individual tocopherols, high-performance liquid chromatography, gas chromatography, and the combined techniques high-performance liquid chromatography-mass spectrometry and gas chromatography-mass spectrometry are employed $[33,34]$. Further studies in this area would be desirable to more precisely distinguish the actual vitamin $\mathrm{E}$ deficiency in the various conditions by measuring serum levels in patients with malabsorptive disorders (celiac disease, chronic pancreatitis, and chronic inflammatory bowel diseases), motility disorders (recurrent pseudo-obstruction, myopathy), and in patients with chronic atresia or atonia and after bariatric surgery $[2,7]$.

In this context, we still need to clarify what role quantitative serum vitamin E levels play (cutoff values for the development of brown bowel syndrome). For the pathological diagnosis based on small bowel biopsy, it is important to know that lipofuscin often cannot be detected with certainty by using conventional hematoxylin-eosin staining. Therefore, if brown bowel syndrome is suspected, e.g. in conjunction with recurring motility disorders of thus far unexplained etiology or when a brown-golden coloration of the small bowel is apparent endoscopically or macroscopically (differential diagnosis Whipple disease), the pathologist should be informed accordingly about these particular findings. Further specialized histological examinations can then be performed to confirm or exclude the presence of this disease. Here, supplementary UV light microscopy is mainly applied or electron microscopy is used for evaluation $[9,35]$.

Several authors have reported for confirmed brown bowel syndrome that long-term vitamin supplementation improved the malabsorption syndrome and was accompanied by regression of the lipofuscin deposits [26]. The required daily dose of vitamin $\mathrm{E}$ for brown bowel syndrome depends on the serum levels of vitamin, clinical symptoms, and supply of polyunsaturated fatty acids. Generally, the dose of vitamin E for therapeutic substitution lies between 250 and 1,000 IU of vitamin E (corre- 
sponding to $150-600 \mathrm{mg}$ per day). For comparison, the dose of vitamin $\mathrm{E}$ for prophylactic supplementation for adults is $20-35 \mathrm{mg}$ per day.

\section{Conclusion}

Diseases involving chronic severe malabsorption are rare; however, they can develop in individual cases of refractory small bowel disease, advanced chronic pancreatitis, or liver diseases, result from a lack of vitamin E, or also develop as a complication of malabsorptive bariatric surgery. These conditions are also associated with the risk of brown bowel syndrome, which in turn induces further disease symptoms, recurring motility disorders, and diarrhea. Therefore, for the treatment of malabsorption syndromes and diseases of the liver and pancreas, the development of brown bowel syndrome associated with the aforementioned symptoms should be considered for differential diagnosis in order to initiate treatment with vitamin E supplementation and/or other fat-soluble vitamins in a timely manner.

\section{References}

$>1$ Dror DK, Allen LH: Vitamin E deficiency in developing countries. Food Nutr Bull 2011; 32:124-143.

$>2$ Lee H, Carlin AM, Ormsby AH, Lee MW: Brown bowel syndrome secondary to jejunoileal bypass: the first case report. Obes Surg 2009;19:1176-1179.

$>3$ Foster CS: The brown bowel syndrome: a possible smooth muscle mitochondrial myopathy? Histopathology 1979;3:1-17.

4 Ruchti C, Eisele S, Kaufmann M: Fatal intestinal pseudo-obstruction in brown bowel syndrome. Arch Pathol Lab Med 1990;114:76-80.

$\checkmark 5$ Toffler AH, Hukill PB, Spiro HM: Brown bowel syndrome. Ann Intern Med 1963;58: 872-877.

6 Horn T, Svendson LB, Nielsen R: Brownbowel syndrome: review of the literature and presentation of cases. Scand J Gastroenterol 1990;25:66-72.

$>7$ Oberhuber G, Pointner R, Lauer E, Waldenberger P, Radaszkiewicz T: 'Brown bowel' syndrome - lipofuscinosis of the intestine as a cause of atonia (in German). Leber Magen Darm 1989;19:270-274.

$>8$ Kaiserling E, Schaffer R, Weckermann J: Brown bowel syndrome with manifestation in the gastrointestinal tract and thyroid gland. Pathol Res Pract 1988;183:65-79.

$>9$ Dudorkinova D, Povysil C: The brown bowel syndrome (in Czech). Cesk Pathol 1994;30: 23-26.

10 Horn T, Svendsen LB, Johansen A, Backer O: Brown bowel syndrome. Ultrastruct Pathol 1985;8:357-361.

$>11$ Lin CN, Huang AH, Hsu SI, et al: Brown bowel syndrome: report of two cases. J Formos Med Assoc 1993;92:1090-1094.

$\checkmark 12$ Lee SP: Vitamin E treatment for brown bowel syndrome. Mayo Clin Proc 1979;54:752.

$\checkmark 13$ Michowitz M, Noy S, Chayen D, Baratz M, Bawnik JB: Brown-bowel syndrome. Am Surg 1989;55:566-569.

- 14 Hozyasz KK, Chelchowska M, LaskowskaKlita T: Vitamin E levels in patients with celiac disease (in Polish). Med Wieku Rozwoj 2003;7:593-604.
15 Anand A, Jaffe BM: Brown bowel syndrome: case report and review. J La State Med Soc 2005; 157:338-340.

16 Hitzman JL, Weiland LH, Oftedahl GL, Lie JT: Ceroidosis in the 'brown bowel syndrome'. Mayo Clin Proc 1979;54:251-257.

-17 Drake WM, Winter TA, Price SK, O’Keefe SJ: Small bowel intussusception and brown bowel syndrome in association with severe malnutrition. Am J Gastroenterol 1996;91:1450 1452 .

18 Robinson MH, Dowling BL, Clark JV, Mason $\mathrm{CH}$ : Brown bowel syndrome: an unusual cause of massive dilatation of the colon. Gut 1989;30:882-884.

19 Michaely HJ, Daroca PJ, Plvsic BM: Brown bowel syndrome - an unusual etiology of pseudo-obstruction of the small intestine (in German). Rofo 2003;175:1143-1144.

20 Hurley JP, Leary R, Connoly CE, Keeling P: Massive lower gastrointestinal bleeding in association with the brown bowel syndrome. J R Soc Med 1991;84:437-438.

21 Shiller M, Cohen I, Munichor M, Loberant N, Bickel A, Reshef R: The 'brown bowel syndrome' associated with jejunal carcinoma. Am J Gastroenterol 1993;88:1788-1789.

22 Reynaert H, Devis G: The brown bowel syndrome and gastrointestinal adenocarcinoma. Am J Gastroenterol 1994;89:812-813.

23 Reynaert H, Debeuckelaere S, De Waele B, Meysman M, Goossens A, Devis G: The brown bowel syndrome and gastrointestinal adenocarcinoma. Two complications of vitamin $\mathrm{E}$ deficiency in celiac sprue and chronic pancreatitis? J Clin Gastroenterol 1993;16:48-51.

-24 Narvaez Rodriguez I, Herrera Justiniano JM, Marquez Galan JL, et al: The brown bowel syndrome. A case report (in Spanish). Rev Esp Enferm Dig 1993;83:281-283.

25 Mills PR, Brown IL, Watkinson G: Idiopathic chronic ulcerative enteritis. Report of five cases and review of the literature. Q J Med 1980; 49:133-149.
26 Ward HC, Leake J, Milla PJ, Spitz L: Brown bowel syndrome: a late complication of intestinal atresia. J Pediatr Surg 1992;27:15931595.

27 Lambert JR, Luk SC, Prizker KP: Brown bowel syndrome in Crohn's disease. Arch Pathol Lab Med 1980;104:201-205.

28 Malinowski SS: Nutritional and metabolic complications of bariatric surgery. Am J Med Sci 2006;331:219-225.

29 Waldron D, Horgan P, Barry K, et al: Anorectal functional deficit in the brown bowel syndrome. Ir J Med Sci 1994;163:404-405.

-30 Hentati F, El-Euch G, Bouhlal Y, Amouri R Ataxia with vitamin E deficiency and abetalipoproteinemia. Handb Clin Neurol 2012;103: 295-305.

31 Dutta SK, Bustin MP, Russell RM, Costa BS Deficiency of fat-soluble vitamins in treated patients with pancreatic insufficiency. Ann Intern Med 1982;97:549.

-32 Nakamura T, Takebe K, Imamura K, Tando Y, Yamada N, Arai Y, Terada A, Ishii M, Kikuchi H, Suda T: Fat-soluble vitamins in patients with chronic pancreatitis (pancreatic insufficiency). Acta Gastroenterol Belg 1996; 59:10.

33 Nagy K, Courtet-Compondu MC, Holst B, Kussmann M: Comprehensive analysis of vitamin E constituents in human plasma by liquid chromatography-mass spectrometry. Anal Chem 2007;79:7087-7096.

-34 Melchert HU, Pabel E: Quantitative determination of alpha-, beta-, gamma- and deltatocopherols in human serum by high-performance liquid chromatography and gas chromatography-mass spectrometry as trimethylsilyl derivatives with a two-step sample preparation. J Chromatogr A 2000;896:209215 .

35 Gallager RL: Intestinal ceroid deposition 'brown bowel syndrome'. A light and electron microscopy study. Virchows Arch A Pathol Anat Histol 1980;389:143-151. 